\title{
Physiological cost index of paraplegic locomotion using the ORLAU ParaWalker
}

\author{
A V Nene MB BS DOrth MS(Orth) MchOrth, S J Jennings BSc \\ Orthotic Research \& Locomotor Assessment Unit, The Robert Jones \& Agnes Hunt \\ Hospital, Oswestry, Shropshire, SY10 7AG, England.
}

\begin{abstract}
Energy expenditure is an important parameter in the assessment of gait and orthotic treatment of locomotor disabilities. Up until now oxygen uptake measurement has been the most common method used to assess this. In able bodied subjects heart rate monitoring is also increasingly used. In high thoracic level lesion paraplegics monitoring heart rate was considered to be unreliable because of suspicion of injury to the sympathetic contribution to the cardiac plexus. Bar-On \& Nene ${ }^{1}$ found that in paraplegics below the lesion level T3 heart rate still shows linear relation to oxygen uptake. MacGregor ${ }^{2,3}$ combined the heart rate and speed of locomotion to produce a single index called physiological cost index. This study consists of monitoring heart rate and speed of 16 adult thoracic level paraplegics walking with the ORLAU ParaWalker, calculation of their physiological cost index, and establishing a range of physiological cost index of paraplegic locomotion using the ORLAU ParaWalker.
\end{abstract}

Key words: paraplegia; locomotion; orthosis; heart rate; speed; physiological cost index.

\section{Introduction}

Energy expenditure is an important parameter in the assessment of orthotic treatment of heavily handicapped patients such as paraplegics. The most commonly used physiological parameter for assessment of energy expenditure has been the measurement of oxygen uptake. This technique involves either wearing a noseclip and breathing through a mouthpiece or breathing through a snugly fitting mask so that expired air can be collected into a Douglas bag for analysis. It can also be directly analysed with the oxygen consumption meter (eg Oxylog). However, in clinical situations involving paraplegics this method proves to be impractical; also, not all the institutions involved in walking rehabilitation of paraplegics have respiratory laboratory facilities.

In able bodied subjects heart rate and oxygen uptake have a linear relation up to submaximal workloads. ${ }^{4}$ This has enabled clinicians and rehabilitation engineers to monitor the energy cost of a variety of physical activities by monitoring heart rate alone. Sympathetic regulation of the cardiovascular system has been claimed by various workers to be between thoracic spinal cord levels 1 and $6 .^{5-9}$ This implied that monitoring heart rate as an indicator of energy expenditure was unreliable in cases of upper thoracic level paraplegics.

A study involving 44 traumatic complete paraplegics with lesion levels ranging from T3 to T10 was carried out by Bar-On \& Nene. ${ }^{1}$ Subjects were put through an arm cranking exercise routine with increasing power levels. Their heart rate and oxygen uptake was measured for each power level. A linear relationship was found between heart rate and oxygen uptake in all the paraplegic subjects. This study suggested that the sympathetic contribution to the cardiac plexus is intact in traumatic complete paraplegics with a lesion level below T3. Another possibility suggested was that the cardiac response to an increased demand in the physical exercise state is controlled by some other mechanism. 
In the light of this knowledge the method of measurement of heart rate can also be extended to walking rehabilitation of paraplegics. It has been shown in the past that it was possible to establish walking performance of patients by monitoring speed and heart rate $^{10,11}$. MacGregor ${ }^{2,3}$ described a method of combining the 2 parameters to produce a single index called the physiological cost index (PCI) as an indicator of locomotor efficiency.

Authors believe in using 2 distinct terms as regards energy studies concerning locomotion. These are 'energy consumption' and 'energy cost'. The first denotes the amount of energy utilised per unit of time and the other indicates the amount of energy utilised to traverse a unit distance. Estimation of PCI is preferred to measurement of heart rate alone because it takes into account the speed of locomotion and thereby indicates the energy cost of their locomotion; in other words, it indicates the efficiency of their locomotion.

One of the main interests of ORLAU has been using orthoses for paraplegic locomotion. In the initial period children with myelomeningocoele were supplied with hip guidance orthosis, along the principles described by Rose, ${ }^{12}$ to enable them to ambulate reciprocally. The same principles were applied and the first adult traumatic paraplegic was supplied with a ParaWalker in December 1981. (The name ParaWalker came into being as the orthosis became available for clinical supply.) The principles used in the ParaWalker have been extensively described by Rose ${ }^{12.13}$ and Stallard $e t$ al. ${ }^{14}$

The ParaWalker enables paraplegics to ambulate in a reciprocal fashion using crutches over a variety of surfaces. It has a unique combination of:

1 Rigid body brace which resists adduction or abduction of lower limbs.

2 Hip joints with low coefficient of friction and adjustable stops for flexion and extension.

3 Simple and easy operation of hip and knee joint locks as well as other fastening mechanisms.

4 A high degree of mechanical safety and reliability with reduced maintenance costs.

The purpose of this study was to establish a baseline range of PCI for thoracic level traumatic complete paraplegics ambulating with the ORLAU ParaWalker.

\section{Subjects}

Sixteen subjects participated in this study. There were 14 males and 2 females. All were post trauma complete paraplegics with lesion levels varying from T3 to T12. Their age ranged from 25 years to 50 years. Duration of paraplegia varied from 3 years and 7 months to 21 years and 9 months. All were experienced ParaWalker users. Duration of their ParaWalker use varied from 6 months to 6 years and 3 months. Eight subjects used their ParaWalker once a week. Three subjects used it 3 times a week. Two subjects used it 4 times a week. One subject used it 5 times a week and the remaining 2 subjects used it every day of the week. Their weight plus ParaWalker ranged from $50.9 \mathrm{~kg}$ to $85.9 \mathrm{~kg}$. None of them had any symptoms related to their cardiopulmonary function either in the past or at the time of the test. Table I shows the details of all the subjects.

\section{Method}

\section{Description of telemetry system}

Evaluation of PCI requires the measurement of speed and heart rate whilst walking. Measurement of heart rate is achieved by registering the electrocardiographic (ECG) waveform from electrodes on the chest well.

The ECG signal is amplified before being used to modulate pulses of infra-red. The ECG is effectively sampled at around $6 \mathrm{k} \mathrm{Hz}$. The 6 infra-red emitting diodes (GAL 11, $940 \mathrm{~nm}$ ) are arranged in triplets on each shoulder to give emission over a wide field. To cover the area where the subject may walk, 6 receiver heads are positioned, each containing an array of 14 photodiodes (BPW 41). The system automatically uses the receiver presenting the strongest signal. The ECG waveform is recreated and closely follows the original. 
Table I Details of the subjects

\begin{tabular}{rcccccccc}
\hline No. & Initials & $\begin{array}{c}\text { Age } \\
\text { yrs }\end{array}$ & Sex & $\begin{array}{c}\text { Weight } \\
\text { Kg }\end{array}$ & Level & $\begin{array}{c}\text { Duration of } \\
\text { paraplegia } \\
\text { yrs/months }\end{array}$ & $\begin{array}{c}\text { Duration of } \\
\text { ParaWalker } \\
\text { use yrs/ } \\
\text { months }\end{array}$ & $\begin{array}{c}\text { Frequency } \\
\text { times/week }\end{array}$ \\
\hline 1 & & & & & & & \\
2 & NC & 25 & M & 60.5 & T5 & $3 / 9$ & $2 / 2$ & 1 \\
3 & SR & 27 & M & 63.2 & T6 & $7 / 4$ & $5 / 1$ & 1 \\
4 & WF & 27 & M & 85.9 & T11 & $9 / 2$ & $2 / 4$ & 5 \\
5 & AB & 40 & F & 60.5 & T5 & $4 / 10$ & $3 / 7$ & 4 \\
6 & CT & 31 & F & 55.5 & T4 & $13 / 5$ & $2 / 9$ & 3 \\
7 & IB & 28 & M & 73.4 & T4 & $5 / 8$ & $1 / 6$ & 3 \\
8 & TB & 29 & M & 58.9 & T12 & $5 / 11$ & $3 / 0$ & 3 \\
9 & LH & 31 & M & 64.6 & T6 & $12 / 10$ & $1 / 6$ & 1 \\
10 & PH & 26 & M & 69.1 & T3 & $5 / 5$ & $0 / 9$ & 7 \\
11 & TM & 26 & M & 70.0 & T4 & $3 / 7$ & $1 / 11$ & 1 \\
12 & SM & 28 & M & 73.4 & T8 & $6 / 8$ & $2 / 6$ & 7 \\
13 & KB & 26 & M & 65.0 & T8 & $7 / 9$ & $2 / 1$ & 4 \\
14 & PE & 32 & M & 50.9 & T5 & $13 / 1$ & $0 / 6$ & 1 \\
15 & DF & 50 & M & 65.9 & T10 & $21 / 9$ & $1 / 9$ & 1 \\
16 & MG & 30 & M & 74.1 & T4 & $7 / 2$ & $6 / 3$ & 1 \\
\hline
\end{tabular}

The $\mathrm{R}$ wave is automatically identified within the heart rate detector.

To achieve this the signal is high pass filtered and then half wave rectified. It is then compared with its own average derived from a low pass filter having a time constant of several seconds. A heart beat is registered if a peak occurs above a proportion of this average. After the initial setting up it has not been necessary to adjust this proportion. The detector is able to recognise the $\mathrm{R}$ Wave in all subjects provided that a clean, reasonably stable signal is presented. Any spurious pulse would need to have a peak of at least $75 \%$ the size of the $R$ wave before being misinterpreted as a heart beat. The time period between beats is measured and electronically converted to the heart beat rate. It is only possible to measure rate corresponding to every other inter-beat period.

Pairs of timer gates are positioned $6.1 \mathrm{~m}$ apart. The time taken for the subject to walk from one pair to the other is used to calculate speed. Each pairconsists of a light source and a detector. Interruption of the light path causes an electrical relay to change state and the computer then detects the resulting change in voltage. Hence speed can be calculated as the quotient of the known distance between the markers and time taken.

Heart rate is monitored as the subject walks between the pairs of gates and the last reading is taken by the computer and used in the evaluation of PCI. This final value is compared with an extrapolation based on a linear regression through all the heart rates from the start and the investigator is alerted if there is a discrepancy of more than 5 bts $\min ^{-1}$.

\section{Application of telemetry system}

On arrival in the department subjects were asked to don their ParaWalker. They were weighed in their orthosis. Two self adhesive electrodes were applied to their chest wall, one was fixed to the skin just left of the manubrium sternum in the second intercostal space and the other over the apex beat. Low noise cables were used to connect the electrodes to the signal amplifier support on the backpack, which also held the digital encoder and infra-red transmitter.

The subject then rested in his wheelchair. 
Heart rate was monitored for 10 minutes to establish the resting heart rate. Then the subject stood up and waited for a while until the heart rate was stabilised again. On instruction the subject walked along a walkway, in between the timer gates at a steady speed. Subjects used the ParaWalker walk in such a way that either the left or right crutch passed through the timer gate first at both ends. The computer recorded the ambulatory heart rate and the time taken to traverse the distance between the timer gates. The subject walked 5 times along the walkway with a one minute rest period between each walk. At the end of the fifth walk the subject sat down in the wheelchair and rested. Heart rate was monitored during this recovery period until it lowered to a stable rate, or for a maximum of 10 minutes. The lower of the 2 resting rates measured, ie before and after the 5 walks, was used in the calculation of PCI.

From the resting heart rate, the heart rate at the end of each walk and the time taken to traverse the distance between the timer gates, it was possible to calculate the PCI for each walk. The mean of the 5 walks was taken as the PCI of ParaWalker ambulation for each subject. The following formula was used to calculate the PCI:

PCI $\left(\right.$ bts $\left.\min ^{-1}\right)=$

HR at the end of a walk Resting HR

_ (bts $\left.\min ^{-1}\right) \quad\left(\right.$ bts $\left.\min ^{-1}\right)$

$$
\text { Speed }\left(\mathrm{m} \mathrm{min}^{-1}\right)
$$

The test was repeated in 4 subjects on separate occasions to study the repeatability of the procedure.

\section{Assessment of Accuracy}

In order to assess accuracy, PCI was evaluated using measurements taken directly from the ECG waveform together with an independent measure of walking speed, and was compared with the automated system derived value, measured simultaneously.

Duplicated electrodes were attached to the subject and the ECG signal amplified using Neurolog NL 850 and NL 107 amplifiers. An 'umbilical' lead allowed the subject to move freely. The amplified signal was recorded on a digital storage oscilloscope (Gould 4035). This has an inbuilt cursor facility allowing the measurement of time intervals. At the start of the procedure for the automated system rest rate is measured and displayed on the screen. The ECG from the previous $20 \mathrm{~s}$ was recorded at the same time as the displayed rest rate and heart rate was calculated from the last 20 beats. This measurement was done 5 times in each of 3 subjects.

The output from the timer gates was connected to the oscilloscope in such a way that interruption of the light path caused the signal to change from a high to a low voltage state. From this an independent measure of speed could be made. The normal procedure for the automated system was followed but for each walk the ECG and the states of the timer gates were recorded on the oscilloscopes. PCI was evaluated from the oscilloscope readings for each walk. However, the automatically derived estimate of resting heart rate was used. This procedure was carried out in 5 able bodied subjects.

From 15 measurements the mean discrepancy in resting heart rate between the direct and the system measured values was 1.0 bts $\min ^{-1}$ with standard deviation 0.4 bts $\min ^{-1}$.

Table II shows values of PCI evaluated using the automated system and using the direct measurements. Two values for the direct measurements are presented for each subject, the first column using the resting heart rate from the automated system and the second column the resting rate2 bts $\min ^{-1}$. These represent the extremes in the uncertainty of using the resting heart rate from the automated system. The percentage discrepancy shown is calculated using the value of the direct PCI which gives the greatest value, ie the worst case.

The effect of errors in the measurement of resting or walking heart rate on the calculated value of PCI will depend on the elevation of heart rate. A small elevation in heart rate, for example $10 \mathrm{bts} \mathrm{min}^{-1}$, would imply a large relative error (the error divided by the value) and this would be carried over to the error in the PCI. Conversely a large heart rate elevation 
Table II PCI (bts $\mathrm{m}^{-1}$ ) evaluated using the automated system compared with independent evaluation from the ECG waveform. Each value is the mean of 5 walks.

\begin{tabular}{lccccc}
\hline Subject & $\begin{array}{c}\text { Automated } \\
\text { system }\end{array}$ & a Independent & \% discrepancy & $\begin{array}{c}\text { Heart rate } \\
\text { elevation } \\
\text { btsmin }\end{array}$ \\
\hline 1 & 0.173 & 0.152 & 0.181 & 13.8 & 13 \\
2 & 0.161 & 0.169 & 0.190 & -15.3 & 15 \\
3 & 0.353 & 0.342 & 0.368 & -4.1 & 28 \\
4 & 0.371 & 0.384 & 0.406 & -8.6 & 35 \\
5 & 0.303 & 0.300 & 0.321 & -5.6 & 26 \\
\hline
\end{tabular}

a: lowest estimate of independent PCI using resting heart rate from the automated system; b: highest estimate using the resting heart rate from the automated system -2 bts $\min ^{-1}$

would result in a smaller relative error and more confidence in the results. From the table it can be seen that the subjects with the lowest heart rate elevations also have the greatest discrepancies between methods.

In the clinical situation patients with locomotor disorders will be likely to have larger increases in heart rate on walking than able bodied subjects. This would have the effect of reducing inaccuracies. Walking speeds may also be reduced and since this is evaluated from a measurement of time duration, inaccuracies would lead to a smaller error in PCI.

\section{Results}

Table III shows the resting heart rate, mean of heart rates at the end of each of the 5 walks and walking speeds achieved by the subjects and their respective physiological cost index. Walking speed ranged from $10.06 \mathrm{~m} \mathrm{~min}^{-1}$ to $26.58 \mathrm{~m} \mathrm{~min}^{-1}$. The mean speed was $16.94 \mathrm{~m} \mathrm{~min}^{-1}$. The mean physiological cost index was $3.11 \mathrm{bts} \mathrm{m}^{-1}$. It ranged from $1.47 \mathrm{bts} \mathrm{m}^{-1}$ to $4.76 \mathrm{bts} \mathrm{m}^{-1}$.

Table IV shows the results of repeat tests performed in 4 subjects. In 3 subjects out of 4 , the difference in PCI was less than $10 \%$ of that obtained on the first occasion. In the

Table III Results

\begin{tabular}{rccccc} 
No. & Initials & $\begin{array}{c}\text { Resting } \\
\text { heart rate } \\
\text { bts min }\end{array}$ & $\begin{array}{c}\text { End walk } \\
\text { heart rate } \\
\text { (mean) } \\
\text { bts min }\end{array}$ & $\begin{array}{c}\text { Speed } \\
\text { (mean) } \\
\text { m min }^{-1}\end{array}$ & $\begin{array}{c}\text { PCI } \\
\text { (mean) } \\
\text { bts m }^{-1}\end{array}$ \\
\hline 1 & NC & 98 & 124 & 17.31 & 1.5 \\
2 & SH & 72 & 121.8 & 12.68 & 3.93 \\
3 & SR & 90 & 122 & 20.03 & 1.6 \\
4 & WF & 77 & 152.4 & 21.09 & 3.58 \\
5 & AB & 102 & 164.6 & 23.26 & 2.69 \\
6 & CT & 104 & 151.2 & 10.27 & 4.6 \\
7 & IB & 86 & 149.8 & 16.7 & 3.82 \\
8 & TB & 90 & 129.2 & 26.58 & 1.47 \\
9 & LH & 106 & 169.6 & 22.13 & 2.87 \\
10 & PH & 84 & 106.4 & 15.27 & 1.47 \\
11 & TM & 78 & 123.4 & 10.06 & 4.51 \\
12 & SM & 72 & 130.6 & 15.85 & 3.7 \\
13 & KB & 92 & 143 & 19.32 & 2.64 \\
14 & PE & 79 & 136 & 11.98 & 4.76 \\
15 & DF & 56 & 95.8 & 11.98 & 3.32 \\
16 & MG & 66 & 120.4 & 16.49 & 3.3 \\
\hline
\end{tabular}


Table IV Results of the repeat test in 4 subjects. (Figures in brackets are those of the first test)

\begin{tabular}{lcccccc}
\hline No. Initials & $\begin{array}{c}\text { Resting } \\
\text { heart rate } \\
\text { bts min }{ }^{-1}\end{array}$ & $\begin{array}{c}\text { End walk } \\
\text { heart rate } \\
\text { (mean) } \\
\text { bts min }\end{array}$ & $\begin{array}{c}\text { Speed } \\
\text { (mean }) \\
\text { m min }^{-1}\end{array}$ & $\begin{array}{c}\text { PCI } \\
\text { (mean) } \\
\text { bts m }\end{array}$ & $\begin{array}{c}\text { Difference } \\
\text { in PCI } \\
\%\end{array}$ \\
\hline 1 & SH & $78(72)$ & $128.2(121.8)$ & $13.1(12.68)$ & $3.82(3.93)$ & -3 \\
2 & SR & $82(90)$ & $119.8(122)$ & $20.82(20.03)$ & $1.82(1.6)$ & 14 \\
3 & WF & $90(77)$ & $149(152.4)$ & $20.89(21.09)$ & $3.3(3.58)$ & -8 \\
4 & AB & $89(102)$ & $147.2(164.6)$ & $22.91(23.26)$ & $2.54(2.69)$ & -6 \\
\hline
\end{tabular}

other subject the difference was about $14 \%$. Since 3 factors, namely heart rate at the end of the walk, resting heart rate and walking speed, are taken into consideration in calculating the PCI any one factor or more in any combination will produce a change in the PCI. These 4 subjects did not show any set pattern of change. Parameters seemed changed at random.

\section{Discussion}

The physiological cost index in the present study group shows wide variation. There was no correlation between PCI and the level of spinal cord lesion and between PCI and the weight of the subject (correlation coefficients -0.23 and -0.27 respectively). It also does not show any relationship to either the duration of ParaWalker use or to the frequency of usage. Nene \& Patrick ${ }^{15}$ measured the oxygen uptake of ParaWalker users to calculate the energy cost of their locomotion. In that study as well it was found that there was no relationship between the level of lesion, duration of ParaWalker use and energy requirements.

Since in the calculation of PCI both the change in subjects' heart rate and speed are taken into consideration, authors feel that it gives a true indication of the efficiency of locomotion of subjects. A small difference between the walking heart rate and the resting heart rate and/or faster walking speed will produce a low PCI. Similarly a large difference in the heart rate and/or slower walking speed will produce a high PCI. The difference in heart rates will depend upon the physiological status of an individual and also upon the efforts required to ambulate with the orthosis. The efforts required will be dependent on mechanical properties of the orthosis. This will be reflected in walking speed of the user. In clinical context of its usage the estimation of PCI appears to be reasonably reproducible, hence it will be very appropriate as an indicator of energy expenditure for an individual using different orthoses or trying out modifications to the same orthosis. It will indicate the physical status of a subject using the same orthosis during the training period. Direct comparison of the PCI of an individual using the ParaWalker to the PCI of another individual using a different orthosis is unrealistic. But it would be reasonable to compare the range of PCIs of a sufficiently large group of subjects using the ParaWalker to the PCIs of another similar group of subjects using different orthoses, eg bilateral long leg braces or reciprocating gait orthosis.

The findings of this study establish a base line range of PCI for the ParaWalker group. This study enables the researchers working with the functional electrical stimulation (FES) to compare the effect of various strategies of hybridisation of the ParaWalker. As mentioned before, researchers working with the other forms of orthosis can compare the efficiency of their orthosis to the ParaWalker.

\section{References}

1 Bar-On ZH, Nene AV (1990) Relationship between heart rate and oxygen uptake in thoracic level paraplegics. Paraplegia 28: 87-95. 
2 MacGregor J (1979) The objective measurement of physical performance with long term ambulatory physiological surveillance equipment (LAPSE). In: Stott FD, Raftery EB, Goulding L, eds. Proceedings of 3rd International Symposium on Ambulatory Monitoring. Academic Press, London: 29-39.

3 MacGregor J (1981) The evaluation of patient performance using long term ambulatory monitoring technique in the domiciliary environment. Physiotherapy 67: 30-33.

4 Astrand PO, Rodhal K (1977) Textbook of Work Physiology. McGraw Hill New York.

5 Guttmann L (1976) Spinal Cord Injuries. Comprehensive Management and Research. 2nd ed. Blackwell Scientific Publishers, Oxford.

6 Silver JR (1971) Vascular reflexes in spinal shock. Paraplegia 8: 231-42.

7 Lindan R, Joiner E, Freehafer AA, Hazel C (1980) Incidence and clinical features of autonomic dysreflexia in patients with spinal cord injury. Paraplegia 18: $285-92$.

8 Frankel HL, Mathias CJ (1980) Severe hypertension in patients with high spinal cord lesion undergoing electro-ejaculation management with prostaglandin E2. Paraplegia 18: 293-99.

9 Coutts KD, Rhodes EC, McKenzie DC (1983) Maximal exercise responses of tetraplegics and paraplegics. $J$ Appl Physiol 55: 479-82.

10 Stallard J, Rose GK, Tait JH, Davies JB (1978) Assessment of orthosis by means of speed and heart rate. J Med Eng Technol 2: 22-24.

11 Stallard J, Rose GK (1980) Clinical decision making with the aid of ambulatory monitoring of heart rate. Prosthet Orthot Int 4: 91-96.

12 Rose GK (1979) The principles and practice of hip guidance articulations. Prosthet Orthot Int 3: $37-43$.

13 Rose GK (1980) Orthoses for the severely handicapped - rational or empirical choice. Physiotherapy 66: 76-81.

14 Stallard J, Major RE, Poiner R, Farmer IR, Jones N (1986) Engineering design considerations of the ORLAU ParaWalker and FES hybrid system. Eng Med 15: 123-129.

15 Nene AV, Patrick JH (1989) Energy cost of paraplegic locomotion with the ORLAU ParaWalker. Paraplegia 27: 5-18. 